\title{
ARTICLE
}

\section{Influence of Radioactive Gas on Particle Size Measurement of Radioactive Aerosol with Diffusion Battery Method}

\author{
Naoyuki OSADA ${ }^{1 *}$, Yuichi OKI ${ }^{2}$, Keizou YAMASAKI ${ }^{2}$ and Seiichi SHIBATA ${ }^{2}$ \\ ${ }^{1}$ Graduate School of Engineering, Kyoto University, Katsura, Nishikyo-ku, Kyoto, 615-8510, Japan \\ ${ }^{2}$ Research Reactor Institute, Kyoto University, Kumatori, Sennan-gun, Osaka, 590-0494, Japan
}

\begin{abstract}
The diffusion battery is a widely used technique for size measurement of radioactive aerosols in operating accelerators. Unlike other radionuclides, the particle size of ${ }^{13} \mathrm{~N}$ aerosols measured with the diffusion battery is affected by coexisting ${ }^{13} \mathrm{~N}$ gaseous species in air of accelerator rooms. The influence may be caused by ${ }^{13} \mathrm{~N}$ gas adsorption on the collection filters used in the diffusion battery. In this work, the percentage of ${ }^{13} \mathrm{~N}$ gas adsorption on various filters was measured, and effect of the adsorption on results of size measurement with the diffusion battery was estimated. Polytetrafluoroethylene filters were found to be suitable for the diffusion battery measurement because they showed the lowest adsorption percentage. The geometric mean and deviation of the ${ }^{13} \mathrm{~N}$ aerosol without correction for the adsorption were estimated to be larger than those with the correction.
\end{abstract}

KEYWORDS: radioactive aerosol, diffusion battery method, gas adsorption

\section{Introduction}

Recently, high-energy and large-current accelerators have been developed and operated for various applications in many research fields. Accelerated beam induces various nuclear reactions which produces radioactive gas and aerosol in accelerator rooms. The radioactive gas and aerosol are transported to respiratory organs such as bronchial tube, lung, alveolo, etc. and cause internal exposure to workers in such facilities. Ratio of adsorption of radioactive aerosol in the respiratory organs depends on aerosol diameter. The information on diameter of the radioactive aerosols is important for estimation of internal exposure dose. Radioactive aerosols, such as radon-daughter aerosol, have been studied in detail ${ }^{1)}$. Concentrations of radon and radon-daughters and size distributions of radon-daughters in air have been measured at many locations, such as indoors, undergrounds, outdoors, mines, etc. It was reported that radioactive atoms attached to ambient non-radioactive aerosol particles in the formation process of the radon-daughter aerosol. Internal dose is given as a function of the aerosol particle size using an ICRP model ${ }^{2)}$. The concentration and size distribution of the radioactive aerosol produced in accelerator facilities have been tried to be measure with diffusion battery. The diffusion battery is an aerosol-sizing instrument applicable for sub-micron particle size. Various radioactive nuclides were formed in accelerator rooms, and the size of the radioactive aerosols for principal nuclides such as ${ }^{7} \mathrm{Be}$ and ${ }^{11} \mathrm{C}$ was successfully measured with diffusion battery. ${ }^{3)}$ In general, it is, however, difficult to measure the particle size of ${ }^{13} \mathrm{~N}$, the principal radionuclide of electron linear accelerator, because coexisting ${ }^{13} \mathrm{~N}$ gaseous species ${ }^{4}$ in air affect the results of particle size measurement with the diffusion battery. The radioactive aerosol is collected on filters in the diffusion battery. When the radioactive aerosol particles were collected, the radioactive gas is also absorbed on the filters with the aerosol. The adsorption of radioactive gas interferes in exact measurement of the activities of radioactive particle. We measured the activities due to radioactive gas adsorption on some filters applied for the diffusion battery method, and found suitable filters to measure radioactive aerosol in the presence of radioactive gas. It was found that the activity of gas adsorption changed the measured size distribution. Influences of radioactive gas on measurements were estimated.

\section{Experiments}

Irradiation experiments were performed at the electron linear accelerator in the Research Reactor Institute of Kyoto University. The accelerated electron energy and current were $30 \mathrm{MeV}$ and 17-90 $\mu \mathrm{A}$, respectively, in this work. A tantalum target was irradiated with accelerated electrons in the accelerator room to produce neutrons and bremsstrahlung. Radioactive isotopes were produced through nuclear reactions between air and the emitted neutrons or photons. A collection and measurement system for radioactive aerosol and gas were located in the next room of the accelerator room. In order to transport the aerosol and gas to the collection and measurement system, a stainless steel tube line was installed. The inlet of the tube line was placed at the backward of the tantalum target to sample the air which included aerosol and gas in the accelerator room (Figure 1).

The activity in the irradiated air was measured with an ionization chamber at the measurement room. The aerosol was led to the diffusion battery. Size distribution of formed aerosol was measured by the diffusion battery method. The diffusion battery employed is the screen type which consists of stainless steel wire screens, (500 wires per an inch), and a backup filter (DM-800, Gelman Science Inc.) for measurement of radioactive aerosol. The formed nano-size aerosol particle attached to the screens depending on the particle diffusion coefficient. The smaller particle had the smaller penetration ratio (Figure 2). It was assumed that the 


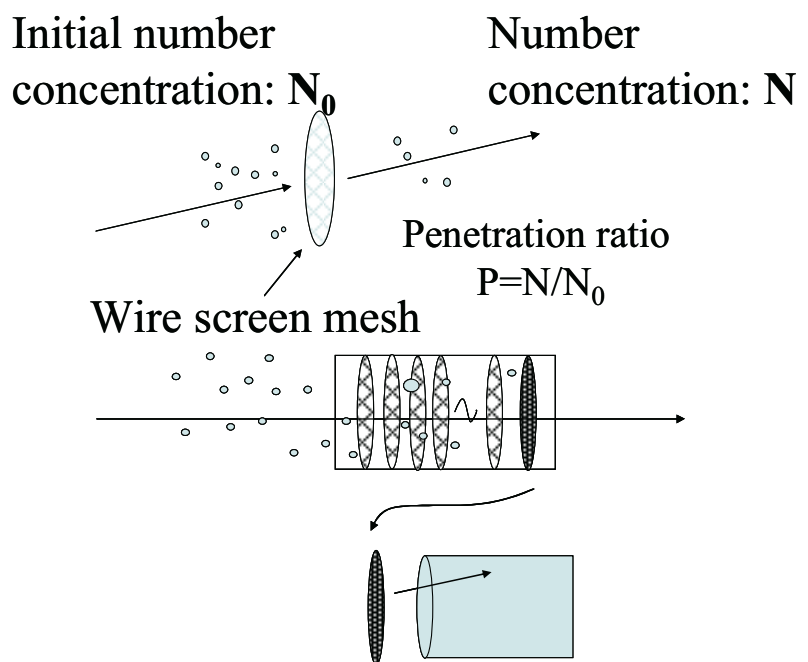

Figure 1 Experimental setup of air irradiation and airborne species measurement

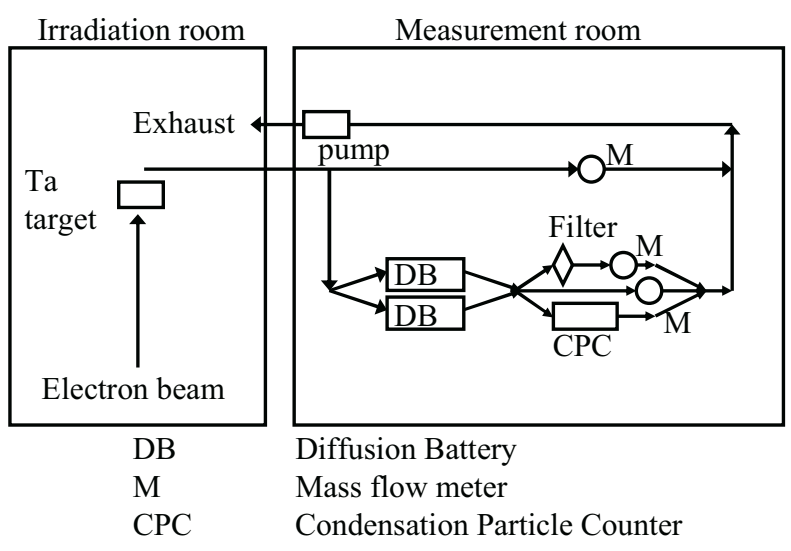

Figure 2 Measurement with diffusion battery

activity indicated the radioactive particle concentration. In non-radioactive aerosol measurement, instead of activity measurement of the backup filter, concentration of particle was measured with Condensation Particle Counter (CPC, TSI Inc., Model 3025A). The size distribution of the aerosol particle was assumed to have a lognormal distribution. The concentrations of penetrated particles are expressed by an integral of multiplication of the penetration ratio and size distribution. A geometric mean diameter (GMD) and geometric standard deviation (GSD) were derived from the penetration ratio ${ }^{5)}$ by a least-squares fitting using the following equations (cgs unit) ${ }^{6}$.

$$
\begin{aligned}
& P(r)=\exp \left\{-\sin \left(\frac{f}{d(r)}\right)^{-\frac{2}{3}}\right\} \\
& d(r)=\frac{b T}{6 \pi v r}\left\{1+1.246 \frac{\lambda}{r}+0.42 \frac{\lambda}{r} \exp \left(-0.87 \frac{r}{\lambda}\right)\right\}
\end{aligned},
$$

where $P(r)$ is penetration ratio, $s$ is the specification number of screen, $n$ is number of screen, $f$ is air flow rate $(\mathrm{L} / \mathrm{min}$. $), b$ is the Boltzmann constant, $T$ is temperature of air $(\mathrm{K}), v$ is viscosity of air, $\lambda$ is mean free path of air molecule and $r$ is radius of aerosol particle.
A high-purity germanium semiconductor detector and a coincidence system consisting of two Bismuth Germanium Oxide (BGO) scintillation detectors were applied to measurement activity on filters. The obtained data of CPC, Ge and BGO detectors were recorded by connected PCs. The Ge detector identified and determined radioactive nuclides. BGO detectors measured the annihilation photons, and determined the ratio of activity of $\beta^{+}$decay nuclides. In order to measure activity of adsorption of radioactive gas on filter, irradiated air was introduced to two the same filters placed in series. The first filter collected radioactive both of aerosol and gas, and the second filter collected only radioactive gas. Examined seven filters were shown in Table 1. The BGO detector system determined the activities of sample filters. The flow rate were tried to set about $20 \mathrm{~L} / \mathrm{min}$.

\section{Results and discussion}

The activity of formed radioactive nuclides in irradiated air was measured with an ionization chamber. The decay of activity gave a ratio of radioactive nuclides by fitting. Concentration of total activity was about $7.1 \mathrm{~Bq} / \mathrm{cm}^{3}$ when the beam current was $90 \mu \mathrm{A}$. The activities of ${ }^{13} \mathrm{~N},{ }^{15} \mathrm{O}$ and ${ }^{11} \mathrm{C}$ were determined to be $43 \%, 23 \%$, and $18 \%$, to total activity respectively in irradiated air. Collected activity of particle on DM-800 filter was measured with Ge semiconductor detector. Gamma-ray spectrum showed the photopeaks of ${ }^{39} \mathrm{Cl}$ and the annihilation peak. ${ }^{13} \mathrm{~N}$ in annihilation peak was over $90 \%$ among all the activities. Activity of the gas was about 10 times higher than that of aerosol particles. It assumed that ${ }^{13} \mathrm{~N}$ was most among the activities contained in the radioactive aerosol in $30 \mathrm{MeV}$ electron linear accelerator. ${ }^{13} \mathrm{~N}$ was primary radionuclide of formed activity, and the analysis was calculated about only ${ }^{13} \mathrm{~N}$.

\begin{tabular}{|c|c|c|}
\hline Filter (diameter $47 \mathrm{~mm}$ ) & $\begin{array}{l}\text { Ratio of gas Flow } \\
\text { activity }(\%) \quad(\mathrm{L} / \mathrm{min}) \\
\end{array}$ & rate \\
\hline $\begin{array}{l}\text { Polycarbonate }(0.8 \mu \mathrm{m} \text { pore, } \\
\text { ADVANTEC) }\end{array}$ & 6.6 & 13.8 \\
\hline $\begin{array}{l}\text { Cellulose acetate } \\
\text { (ADVANTEC) }\end{array}$ & 7.3 & 15.7 \\
\hline $\begin{array}{l}\text { Millipore AA }(0.8 \mu \mathrm{m} \text {, } \\
\text { Millipore })\end{array}$ & 5.6 & 18 \\
\hline $\begin{array}{l}\text { Teflo }(1.0 \mu \mathrm{m} \text { pore, } \\
\text { Lifescience })\end{array}$ & 0.31 & 20 \\
\hline $\begin{array}{l}\text { PTFE }(0.4 \mu \mathrm{m} \text { pore, } \\
\text { ADVANTEC })\end{array}$ & 1.1 & 12 \\
\hline $\begin{array}{l}\text { T60A20 (Teflon binder glass } \\
\text { fiber filter, Lifescience) }\end{array}$ & 19 & 22 \\
\hline \multirow{3}{*}{ DM-800 (Gelman science) } & 3.2 & 19.3 \\
\hline & 13 & 10 \\
\hline & 31 & 3.5 \\
\hline
\end{tabular}

Table 1 Ratio of activities of gas adsorption on filter

Gas adsorption ratio was measured for seven filters. Results were shown in Table 1. Collection efficiency was measured with the CPC which could particles over $6 \mathrm{~nm}$ in 
diameter. The efficiency of the non-radioactive particles exceeded $99.99 \%$. The penetration ratio of non-radioactive aerosol was confirmed with CPC which could count particle over $6 \mathrm{~nm}$ diameter. Gas adsorption was observed in almost all of examined filters. The gas adsorption ratio depended on the material of the filters. Lifescience Teflo and ADVANTEC PTFE which were made of polytetrafluoroethylene adsorbed radioactive gas only 0.3 and $1.1 \%$, respectively. The about $6 \%$ of activity on the Millipore AA was due to the activity of gas. The Millipore AA was well applied for collection of radioactive aerosol. The lower flow rate was applied, the more activity attached to the DM-800 filter. The lower flow rate was applied in the case of the diffusion battery method. More gas adsorbed on filters than Table 1 at diffusion battery method. The diffusion battery method with a CPC and a DM-800 filter determined GMD and GSD obtained by fitting equation (1) to experimental measurements without any correction for the gas adsorption were $184 \mathrm{~nm}, 1.6$ for the radioactive aerosol, $114 \mathrm{~nm}, 1.2$ for the non-radioactive one, respectively. It was assumed that the radioactive gas adsorbed to a DM-800 filter about $20 \%$ of total activity. The influence of radioactive gas was eliminated from counted activity of filter. The gas adsorption rate was assumed to be the same independent of number of screens because the amount of adsorbed gas was negligibly small compared to total gas amount in the air. The corrected GMD and GSD were $136 \mathrm{~nm}$ and 1.2, respectively. The correction of gas adsorption made GMD and GSD smaller. (Figure 3)

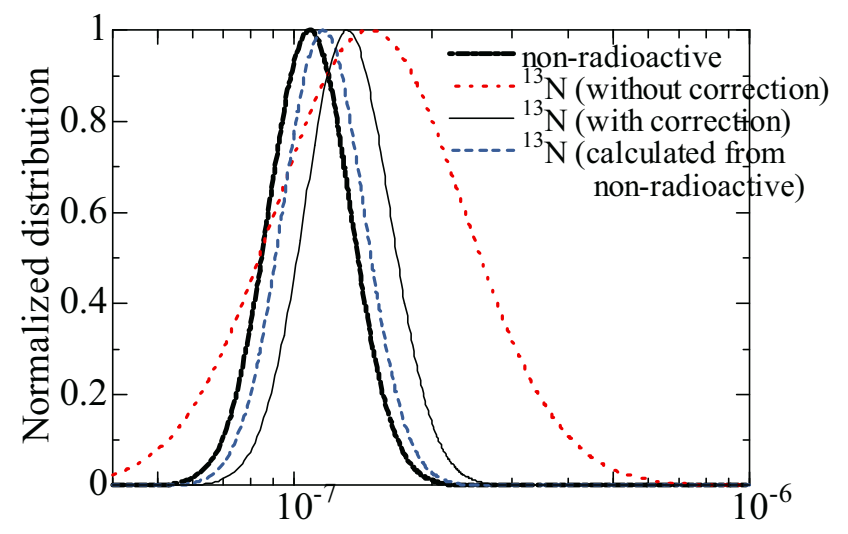

Particle diameter (m)

Figure 3 Particle size distributions of non-radioactive aerosol and radioactive aerosol.

We calculated the distributions of radioactive aerosol from that of non-radioactive aerosol in accelerator room. Assumption of formation mechanism of radioactive aerosol was employed to simple attachment process like a radon-daughter aerosol. ${ }^{7)}$ The corrected GMD and GSD were $121 \mathrm{~nm}$ and 1.2 respectively. Corrected distribution of radioactive aerosol approached the distribution calculated on the basis of the attachment model from non-radioactive aerosol. This correction of radioactive gas was supposed to be appropriate. The radioactive gas adsorbed on the PTFE filter was only $1.1 \%$ to collected activity, and the influence on the measurement of the size distribution was negligible.

Figure 4 shows influences of the coexisting gas on the size measurement of radioactive aerosols as a function of the adsorption ratio of the radioactive gas. The influence was calculated on the assumption which sample filters collected the radioactive gas in addition to the radioactive particles. The penetration function (1) led ratio of penetration of radioactive particle activities collected on the backup filter. Activity of gas was added to the calculated activity on the filter if the radioactive gas was adsorbed. GMD and GSD on the assumption which gas was adsorbed on filters were obtained from estimated the gas added penetration ratio by the fitting. Obtained GMD increased when the adsorption of radioactive gas increased. When ratio of gaseous activity is $50 \%$, the particle diameter of $100 \mathrm{~nm}$ and $50 \mathrm{~nm}$ are calculated to be $365 \mathrm{~nm}$ and $216 \mathrm{~nm}$, respectively.

The larger the particles were, the more particles penetrated the stack of screens and were collected on the backup filter. When more activity of gas was detected on the filter in addition to radioactive particle and regarded as radioactive particle, the obtained diameter of aerosol was shifted to larger and the distribution was broadened. The nano-size particles diffused and are attached to screens. Smaller particle is attached easily to the screen in diffusion battery, which increased ratio of gas to total activity on the filter. The measurement of nano size particles was more influenced from the adsorption of gas.

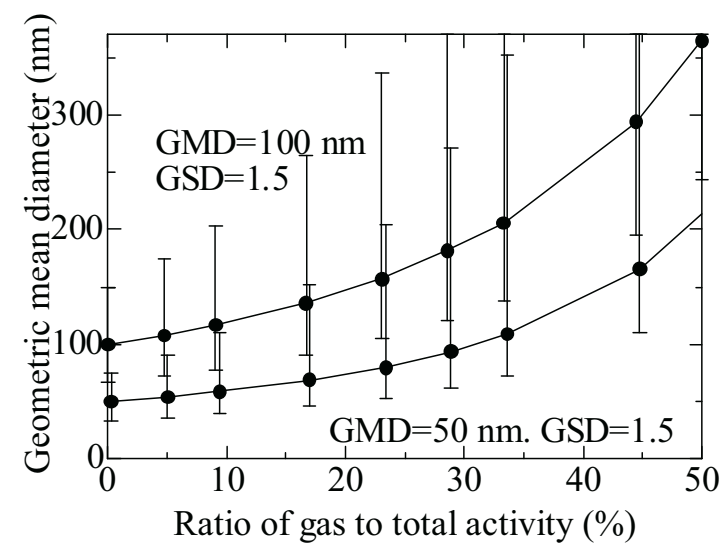

Figure 4 Relationships of ratio of radioactive gas to total activity and obtained GMD and GSD. The error bars represent 1 GSD.

\section{Conclusion}

When particle size measurement of radioactive aerosol was carried out in circumstance in which radioactive gas and aerosol coexist such as accelerator room, the sampling filters collected radioactive gas in addition to radioactive particles. This increase of gaseous activity made distribution of radioactive aerosol larger and broad. Polytetrafluoroethylene filters were found to be suitable for aerosol sampling in accelerators because their gas adsorption ratio was very small. 


\section{References}

1) J. Porstendorfer, "Properties and behavior of radon and thoron and their decay products in the air", J. Aerosol Sci., 25[2], 219 (1994)

2) International Commission on Radiological Protection (ICRP). "Dose coefficients for intakes of radionuclides by workers.", Publication 68, Oxford: Pergamon Press (1994)

3) F. Lucci, S. Merolli and M. Pelliccioni, "Measurement of induced radioactivity in dust around a $400 \mathrm{MeV}$ linac", Health Physics, 24, 411 (1973)

4) A. Endo, M. Kikuchi, S. Izawa and Y. Ikezawa,
"Characteristics of the chemical forms of ${ }^{11} \mathrm{C},{ }^{13} \mathrm{~N}$, and ${ }^{15} \mathrm{O}$ in air by the operation of a $100 \mathrm{MeV}$ electron linear accelerator", Health Physics, 68(1), 80 (1995)

5) Y. S. Cheng and H.C. Yeh, J. Aerosol Sci., 11, 313 (1980)

6) Y. Oki, K. Kondo, Y. Kanda and T. Miura, "Aerosol-size distribution of radon daughter ${ }^{218} \mathrm{Po}$ in the accelerator tunnel air", Journal of Radioanalytical and Nuclear Chemistry, 239[3], 501 (1999)

7) J. Porstendorfer, A. Reineking, K. H. Becker, In radon and its decay products Occurrence, Properties, and Health Effects, ACS-Symposium Series 331, 285 (1987) 